
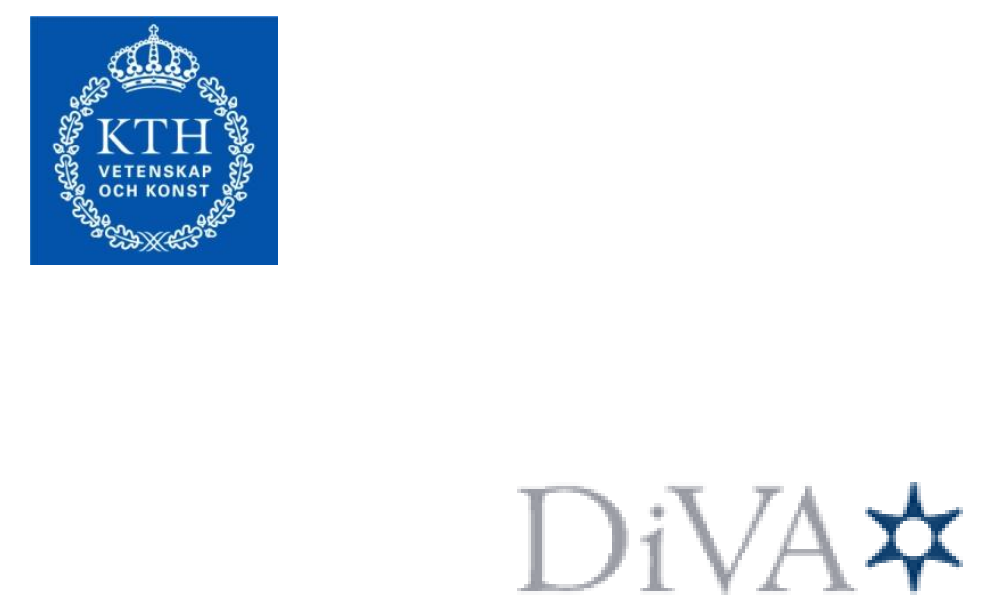

http://kth.diva-portal.org

This is the author's version of a work that was accepted for publication in Nuclear Engineering and Design. Changes resulting from the publishing process, such as peer review, editing, corrections, structural formatting, and other quality control mechanisms may not be reflected in this document. Changes may have been made to this work since it was submitted for publication. A definitive version was subsequently published in Nuclear Engineering and Design, VOL 252, ISSUE 1, (November, 2012), DOI10.1016/j.nucengdes.2012.07.005.

Citation for the published paper:

Suvdantsetseg, E.; Wallenius, J.; Bortot, S Optimization of the reactivity control drum system of ELECTRA Nuclear Engineering and Design, VOL 252, ISSUE 1,pp. 209 - 214 [URL: http://dx.doi. 10.1016/j.nucengdes.2012.07.005

Access to the published version may require subscription. Publish with permission from: Elsevier 
list of table

List of Tables
1. Control drum parameters of the reference design.
2. Parametric analysis of drum geometry.
3. Comparison of upgraded design and the reference design.

List of Tables
1. Control drum parameters of the reference design.
2. Parametric analysis of drum geometry.
3. Comparison of upgraded design and the reference design.

List of Tables
1. Control drum parameters of the reference design.
2. Parametric analysis of drum geometry.
3. Comparison of upgraded design and the reference design.

List of Tables
1. Control drum parameters of the reference design.
2. Parametric analysis of drum geometry.
3. Comparison of upgraded design and the reference design.

List of Tables
1. Control drum parameters of the reference design.
2. Parametric analysis of drum geometry.
3. Comparison of upgraded design and the reference design.

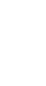

$\sqrt{2}$

List of Tables
1. Control drum parameters of the reference design.
2. Parametric analysis of drum geometry.
3. Comparison of upgraded design and the reference design.

List of Tables
1. Control drum parameters of the reference design.
2. Parametric analysis of drum geometry.
3. Comparison of upgraded design and the reference design.

List of Tables
1. Control drum parameters of the reference design.
2. Parametric analysis of drum geometry.
3. Comparison of upgraded design and the reference design.

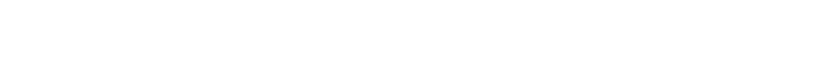

List of Tables
1. Control drum parameters of the reference design.
2. Parametric analysis of drum geometry.
3. Comparison of upgraded design and the reference design.

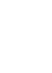

(1)

(1)

(1) 


\section{List of Figures}

1. ELECTRA reference primary system cross section (left) and axial elevation (right).

2. Maximum hot channel cladding mid-wall temperature of the reference design during various reactivity insertions.

3. Drum geometry: absorber angle $\theta$, radius $r$, thickness $d$, and distance between drum and core center $R$.

4. Hot leg and cold leg free surface area.

5. Upgraded core design of ELECTRA.

6. ELECTRA primary system model in SAS4A/SASSYS-1.

7. Maximum cladding mid-wall temperatures in the hot channel during an inadvertent rotation of a single drum. The reference design ( $4.0 \$$ with $0.02 \$ / \mathrm{s}$ rate - blue line) is compared with the upgraded design (1.64 \$ with $0.02 \$ / \mathrm{s}$ - red line and $1.64 \$ / \mathrm{s}$ rate - green line).

8. Signal-flow graph outlining the mutual dependencies among Laplace-transformed parameters (inputs in red, outputs in yellow, state-output variables in blue). 
NOMENCLATURE

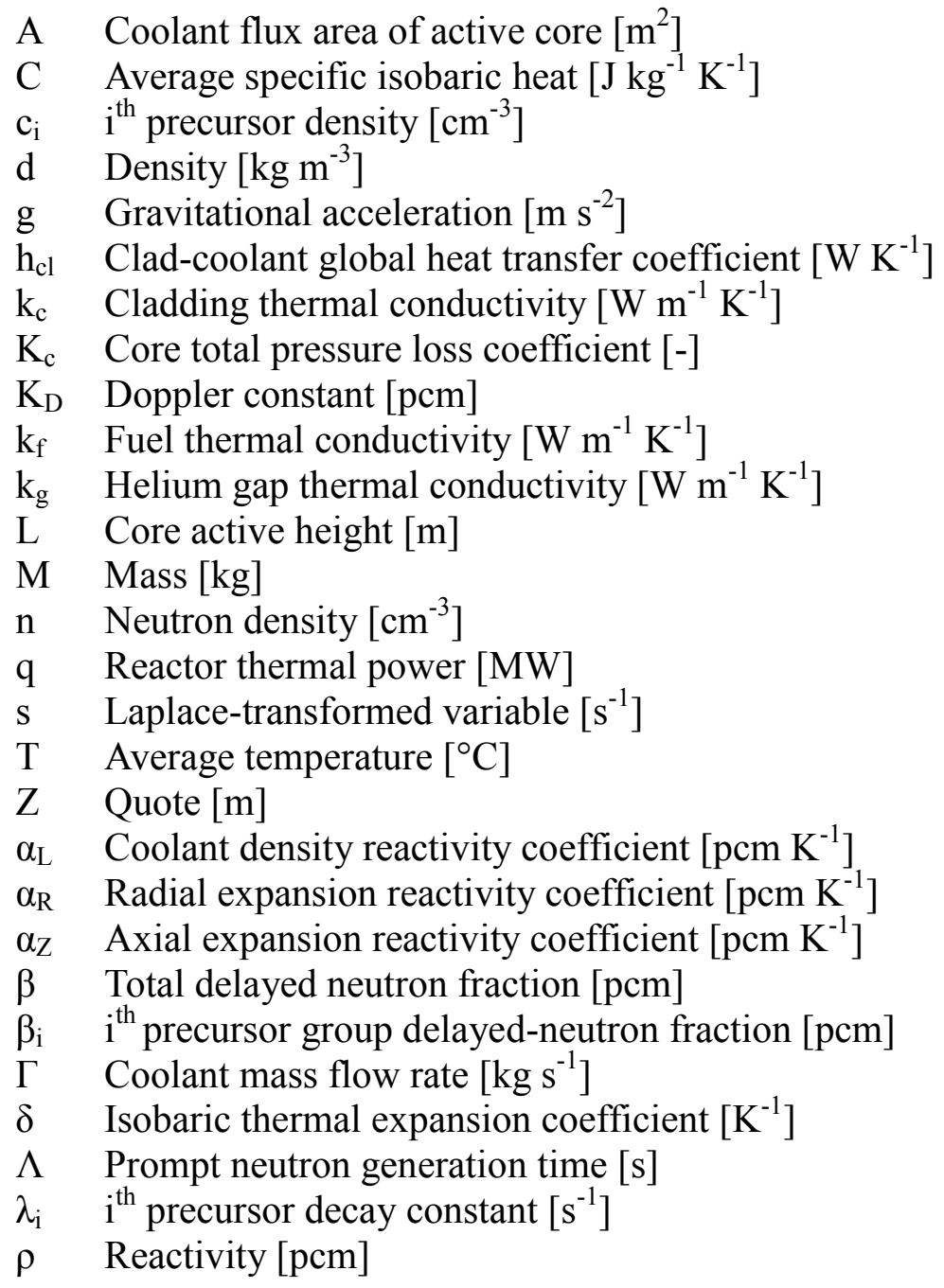

\section{Subscripts and superscripts}

$\begin{array}{ll}0 & \text { Steady-state } \\ \mathrm{c} & \text { Cladding } \\ \text { centr } & \text { Centerline } \\ \text { cold } & \text { Cold pool } \\ \text { eff } & \text { Effective } \\ \mathrm{f} & \text { Fuel } \\ \text { hot } & \text { Hot pool } \\ \text { in } & \text { Inlet } \\ \text { int } & \text { Internal } \\ 1 & \text { Lead coolant } \\ \text { mid } & \text { Middle } \\ \text { out } & \text { Outlet }\end{array}$


surf Surface 


\title{
Optimization of the reactivity control drum system of ELECTRA
}

\author{
Erdenechimeg Suvdantsetseg, Janne Wallenius, Sara Bortot \\ KTH, Division of Reactor Physics \\ AlbaNova University Centre, Roslagstullsbacken 21, 10691 Stockholm, Sweden \\ Tel: +46855378220, Fax: +46855378216, E-mail: esuv@kth.se
}

\begin{abstract}
In this paper, an optimized control drum system for the European Lead Cooled Training Reactor (ELECTRA) is proposed. By changing the number of rotating drums from 6 to 12, we succeed in reducing the maximum rotational worth of a single drum from $4 \$$ to $1.64 \$$. As a consequence, the safety margin during reactivity insertions is significantly improved.
\end{abstract}

Keywords: control drums, core design, reactivity worth, transfer function approach, unprotected transient of overpower

\section{INTRODUCTION}

A previous design of European Lead Cooled Training Reactor (ELECTRA) has been presented by Wallenius et al. (2012) that has the following merits: a very small compact core enables negative safety coefficients, and full design power of $0.5 \mathrm{MW}_{\text {th }}$ is completely removed by natural circulation. Such a small core design is achieved by employing inert matrix $\left(\mathrm{Pu}_{0.4}, \mathrm{Zr}_{0.6}\right) \mathrm{N}$ fuel. Absorber elements are placed outside the core assembly to improve neutron economy. Instead of control rods, enriched $\mathrm{B}_{4} \mathrm{C}$ absorbers are placed in the segments of totally six rotating drums, which are located around the core assembly. These control drums can compensate totally $36 \$$ reactivity, which enables ELECTRA to have a long lifetime to avoid refueling. Main parameters of the reference control drums are shown in Table 1, and the reference core design is shown on Figure 1.

However, there is a certain flaw: the largest insertion of reactivity due to drum rotation occurs at beginning of life and reaches $4 \$$. Transient analyses showed that ELECTRA can handle such an amount of reactivity insertion only if the drum rotation rate is mechanically limited to a suitable value. Even so, margin to the limit of cladding creep rupture at the hot channel hot spot could be insufficient if we consider uncertainties in modeling.

Noting that in some space reactor designs (Nikitin et al., 2000) a larger number of drums were applied, we decided to use such an approach to minimize the rotational worth. In what follows we describe the methodology used for optimizing the control drum design. We then present the optimal configuration as well as its transient performance analysis, and finally discuss some other features of the updated design.

\section{METHODOLOGY}

The cladding steel adopted for ELECTRA is a 15/15Ti austenitic steel originally developed by Sandvik under the designation 12R72 (Wilson, 2011). It has been used in Phénix, and is the reference cladding material for ASTRID as well as MYRRHA. The major failure mechanism during power transients is creep rupture. The reference cladding creep rupture life at beginning of life is estimated by Larson-Miller extrapolation of experimental data for Sandvik's 12R72 tubes (Egnell et al., 1979; Wilson, 2011). It indicates that the cladding creep rupture life at $1450 \mathrm{~K}$ is above 0.5 hours, which is the requested delay of operator intervention. Hence, cladding temperature should not exceed $1450 \mathrm{~K}$ in any design basis condition at beginning of life. In order to find out what reactivity insertion could result in such temperatures, a few transient calculations based on the reference design were made. From Figure 2, it can be seen that the maximum insertion should not exceed $2 \$$. We note that this is similar to the typical pulse rod worth in TRIGA reactors. 
In order to reduce the drum worth to as low as $2 \$$, we used the following methodology: we can consider that drum worth is a function of absorber radius, angle and thickness, and distance between the drum and the core centers (Figure 3). Moreover, one may increase the number of drums, which may allow for using some of them as safety drums. Other variables such as absorber content or different geometrical shapes of the drums were not taken into account. The optimization technique consists in performing a systematic parametric analysis over these variables. As a modeling tool, the Monte Carlo code Serpent version 1.1.16 (Leppänen, 2007) was used applying the JEFF3.1.1 nuclear data library. The model includes detailed specification of core assembly, control drums, lead coolant/reflector, core barrel, vessel and concrete shielding around the vessel (see Figure 1). The supporting steel structure around the core is modeled in a simplified fashion.

\section{RESULTS}

First we started with a parametric analysis of the six rotating drums model. The results showed that a single drum rotation worth cannot be reduced to less than $3.5 \$$ unless the drum radius is lowered to a small value. However, if the drum radius becomes small $(\sim 7 \mathrm{~cm})$, the total reactivity worth decreases dramatically from 36 \$ to 10-12 \$, which is not sufficient to compensate ELECTRA's reactivity swing. Hence, the former ELECTRA design concept with six drums is no longer considered.

For the further investigation, we chose a configuration with twice as many drums as a first order approximation, noting that the desired drum worth is about the half of the reference drum worth. In addition, doubling the number of drums does not break the symmetry of the design. Therefore, the design is modified by introducing twelve drums, and then a set of parametric analyses was performed. The results are shown in Table 2, where total reactivity efficiency and a single drum worth are compared.

Noting that a similar research project carried out for a space reactor design (Craft et al., 2011) showed that $90-120^{\circ}$ absorber angle with 1-2 cm thickness provides efficient and high reactivity, we investigated optimal drum configurations around this range.

As a consequence of the introduction of twelve drums, the total reactivity worth decreased from 36 $\$$ to 20-25 $\$$. This decrease can be explained by noting that the furthest distance of the absorbers from the core is decreased. As a consequence, the operational life will be reduced from 20 to 14 years at full power. However, considering that ELECTRA will not be operating at full power continuously, 14 full power years may correspond to more than 40 years of real time. Hence the currently suggested configuration with twelve drums should be satisfactory with respect to drum numbers. Further, if we added more drums, the total worth would decrease since it would be necessary to reduce the radius in order not to shift their centers from the core center, which would lower their importance.

In Table 2, it can be seen that all the configurations show a single drum worth below $2 \$$, and configurations number 2 and 4 seem to have the highest reactivity worth. However, configuration 2 is strongly subcritical at the shutdown state, hence requiring more fuel pins to be added or number of drums to be rotated away for reaching criticality. Therefore, configuration 4 , featuring a $90^{\circ}$ absorber sector, was chosen for further investigation.

In the next step some design changes have been made: firstly, hot and cold leg flow areas were recalculated. This is due to the fact that control drums are located in the hot leg area (See Figure 4) and changing the size of the drums results in a change of the hot leg free surface area, which consequently can influence the stability of the reactor. Since ELECTRA purely relies on natural 
circulation, flow stability is one of the most important concerns, in order to effectively cool the core. If the flow regime is unstable, perturbations may cause a temporary reduction in flow rate, or even flow reversal, causing unacceptably high cladding temperatures. Our previous study (Wallenius et al., 2012), which is an adopted analytical model for stability of a pool-type reactor by Chen et al. (2010), showed that the potential of flow instability is ensured if the hot leg free surface area is equal to the cold leg one. Thanks to the reduction of the drum size, hot leg and consequently cold leg free surface areas can be reduced leading to a smaller vessel size, and therefore less total construction cost.

Secondly, a few updates such as steel structure at the top and bottom of the core and wire spacers between fuel pins have been added to provide more precise neutronic modeling. The upgraded core design is shown in Figure 5, and some important design parameters are compared with the reference design in Table 3.

\section{TRANSIENT ANALYSIS}

In order to show that the upgraded design ensures sufficient safety margin under relevant accident conditions we have performed an unprotected transient of overpower simulation using the SAS4A/SASSYS-1 code (Cahalan, 2002). A primary circuit model is used, which includes active core channel, connecting hydraulic elements and a simplified heat exchanger. The PRIMAR-4 card which provides detailed description for the hydraulic loop is used for better simulating the natural convection. The model layout is shown on Figure 6. Furthermore, transients were necessarily simulated using the point-kinetic approximation. However, since absorber elements are placed outside the core, the approximation should be valid. Required neutronic coefficients and point kinetic data for SAS4A/SASSYS-1 input are calculated with Serpent code.

The maximum reactivity insertion due to a drum rotation can occur at beginning of life. The calculated cladding temperatures during such a transient are shown in Figure 7.

As we can see, the asymptotic value of the hot channel cladding temperature is far below the temperature in the reference design thanks to the lower reactivity insertion. Even if the drum is completely rotated within a second, the cladding temperature remains below the limit.

As a complementary study, an analytical core model has been developed in parallel with the purpose of catching the governing dynamics of the coupled physics in a transfer function approach perspective, which is useful to guarantee a deeper comprehension of the far more accurate and complex transient simulations performed by SAS4A/SASSYS-1 (see Appendix A).

\section{CONCLUSIONS}

We have presented an optimized control drum system for ELECTRA. The maximum rotational worth of a single drum is reduced from $4.0 \$$ to $1.64 \$$ and total reactivity swing of the system results $24 \$$. The analysis of an unprotected transient of overpower shows that the cladding temperature of the hot pin is at least several hundred Kelvin below the temperature at which cladding creep rupture could occur. Hence the safety margin of the upgraded design is significantly better during the investigated design basis event. 


\section{APPENDIX A}

A zero-dimensional model has been implemented incorporating a point-wise kinetics description for neutronics (Equations 1 and 2) coupled with a single-channel, average-temperature heat transfer treatment for thermal-hydraulics (Equations 3 to 7), in which natural circulation of the coolant has been treated by applying the integral momentum balance over the core zone (Equation 8):

$$
\begin{aligned}
& \frac{\mathrm{dn}(\mathrm{t})}{\mathrm{dt}}=\frac{\rho(\mathrm{t})-\beta}{\Lambda} \mathrm{n}(\mathrm{t})+\sum_{\mathrm{i}=1}^{6} \lambda_{\mathrm{i}} \mathrm{c}_{\mathrm{i}}(\mathrm{t}) \\
& \frac{d c_{i}(t)}{d t}=\frac{\beta_{i}}{\Lambda} n(t)-\lambda_{i} c_{i}(t) \\
& \mathrm{M}_{\mathrm{f}} \mathrm{C}_{\mathrm{f}} \frac{\mathrm{dT}_{\mathrm{f}}{ }^{\text {centr }}(\mathrm{t})}{\mathrm{dt}}=\mathrm{q}(\mathrm{t})-\mathrm{k}_{\mathrm{f}}\left(\mathrm{T}_{\mathrm{f}}^{\text {centr }}(\mathrm{t})-\mathrm{T}_{\mathrm{f}}{ }^{\text {surf }}(\mathrm{t})\right) \\
& M_{g} C_{g} \frac{d T_{f}^{\text {surf }}(t)}{d t}=k_{f}\left(T_{f}^{\text {centr }}(t)-T_{f}^{\text {surf }}(t)-k_{g}\left(T_{f}^{\text {surf }}(t)-T_{c}^{\text {int }}(t)\right)\right. \\
& \mathrm{M}_{\mathrm{c}} \mathrm{C}_{\mathrm{c}} \frac{\mathrm{dT}_{\mathrm{c}}^{\text {int }}(\mathrm{t})}{\mathrm{dt}}=\mathrm{k}_{\mathrm{g}}\left(\mathrm{T}_{\mathrm{f}}^{\text {surf }}(\mathrm{t})-\mathrm{T}_{\mathrm{c}}^{\text {int }}(\mathrm{t})\right)-\mathrm{k}_{\mathrm{c}}\left(\mathrm{T}_{\mathrm{c}}^{\text {int }}(\mathrm{t})-\mathrm{T}_{\mathrm{c}}^{\text {surf }}(\mathrm{t})\right) \\
& \mathrm{M}_{c} \mathrm{C}_{\mathrm{c}} \frac{\mathrm{dT}_{\mathrm{c}}{ }^{\text {surf }}(\mathrm{t})}{\mathrm{dt}}=\mathrm{k}_{\mathrm{c}}\left(\mathrm{T}_{\mathrm{c}}{ }^{\text {int }}(\mathrm{t})-\mathrm{T}_{\mathrm{c}}{ }^{\operatorname{surf}}(\mathrm{t})\right)-\mathrm{h}_{\mathrm{cl}}\left(\mathrm{T}_{\mathrm{c}}{ }^{\operatorname{surf}}(\mathrm{t})-\mathrm{T}_{\mathrm{l}}(\mathrm{t})\right) \\
& \mathrm{M}_{\mathrm{l}} \mathrm{C}_{\mathrm{l}} \frac{\mathrm{dT}_{\mathrm{l}}(\mathrm{t})}{\mathrm{dt}}=\mathrm{h}_{\mathrm{cl}}\left(\mathrm{T}_{\mathrm{c}}^{\text {surf }}(\mathrm{t})-\mathrm{T}_{\mathrm{l}}(\mathrm{t})\right)-\Gamma(\mathrm{t}) \mathrm{C}_{\mathrm{l}}\left(\mathrm{T}_{\mathrm{l}}^{\text {out }}(\mathrm{t})-\mathrm{T}_{\mathrm{l}}^{\text {in }}(\mathrm{t})\right)
\end{aligned}
$$

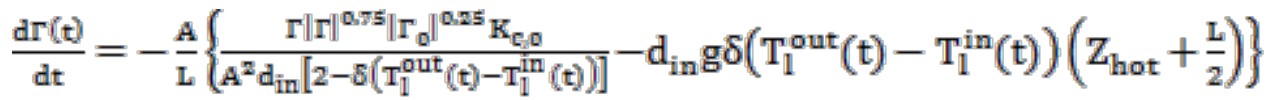

Consistently with the lumped parameter modeling employed, the reactivity feedback is expressed as a function of the average values of fuel and coolant temperatures, while externally introduced reactivity associated with the rotational angle of a representative control drum is handled as a simple input parameter:

$\rho(t)=K_{D}\left(\ln \frac{T_{f}^{\text {eff }}(t)}{T_{\mathrm{f}_{0,0}}^{\text {eff }}}\right)+\alpha_{\mathrm{z}}\left(\mathrm{T}_{\mathrm{f}}^{\text {mid }}(\mathrm{t})-\mathrm{T}_{\mathrm{f}, 0}{ }^{\text {mid }}\right)+\left(\alpha_{\mathrm{R}}+\alpha_{\mathrm{L}}\right)\left(\mathrm{T}_{\mathrm{l}}(\mathrm{t})-\mathrm{T}_{\mathrm{l}, 0}\right)+\rho_{d r u m}(\mathrm{t})$

The above equations have been implemented in MATLAB/SIMULINK ${ }^{\circledR}$ (The MathWoks Inc., 2012) and then linearized around the nominal equilibrium in order to derive an equivalent continuous-time Linear Time-Invariant (LTI) system expressed in terms of state, input and output variables. The model has been finally Laplace-transformed, and the global transfer functions have been drawn. The signal-flow graph in Figure 8 yields a useful representation of the mutual interdependencies among parameters and highlights the governing dynamics of the system.

The mathematical model and its linearized state-space version have been benchmarked against the reference SAS4A/SASSYS-1 model by simulating an unprotected reactivity insertion lying in the range of small perturbations (Figure 9), with the aim at providing a measure of the suitability of such a transfer function approach in the case of a strongly non-linear system.

Due to the zero-dimensional approach adopted in the analytical model, global parameters such as power and total reactivity are selected for the comparison. Discrepancies between the two models have turned out to be slight and mostly due to the simplified treatment of both the reactivity function and the momentum balance. As far as the former is concerned, axial and coolant expansion 
coefficients are calculated at nominal conditions and kept constant during the transient simulation, whereas SAS4A/SASSYS-1 provides time and space dependent feedbacks, which therefore are characterized by different time constants and values. Regarding the latter, a constant core total loss coefficient is adopted instead of correlations for friction and form pressure drops, the accelerative term is neglected, and average lead densities are considered, resulting in a far simpler treatment compared with SAS4A/SASSYS-1. Anyway, the absolute figures differ by some percentages at the most, confirming the applicability of the linear method for investigating ELECTRA dynamics. 


\section{REFERENCES}

Cahalan, J. E., 2002. SAS4A/SASSYS-1 Maintenance and Operations Handbook. Argonne National Laboratory.

Chen, X-N. et al, 2010. Safety analysis of the lead-bismuth eutectic cooled accelerator driven system XT-ADS. Proc. of ICONE18.

Craft, A. E., King, J. C., 2011. Reactivity control schemes for fast spectrum space nuclear reactors. Nucl. Eng. Des., 241, 5.

Egnell, L. et al., quoted in Andersson, T. et al, 1979. Structure and properties of a $19 \mathrm{Cr}-25 \mathrm{Ni}-$ Mo-Ti steel. in Proc. of MiCon 78, ASM STP 672.

Leppänen, J., 2007. Development of a new Monte Carlo reactor physics code. PhD thesis, University of Helsinki.

MATLAB/SIMULINK ${ }^{\circledR}$ Software, The MathWoks Inc., 2012.

Nikitin, V.P. et al., 2000. 'Yenisei' space nuclear power system. Atomic Energy, 88, 2.

Wallenius, J. et al., 2012. ELECTRA: European Lead Cooled Training Reactor. Nucl. Tech., 177,3 .

Wilson, A., 2011. Sandvik Tubes for Nuclear Applications. GenIVFin Workshop, Lappeenranta, Finland, September 30 . October 1. 


\begin{tabular}{|l|c|}
\hline Parameters & Value \\
\hline Number of drums [-] & 6 \\
\hline Boron enrichment [at.\%] & 90 \\
\hline Absorber segment angle [ ${ }^{\circ}$ ] & 180 \\
\hline Drum inner/outer diameter [mm] & $240 / 260$ \\
\hline
\end{tabular}




\begin{tabular}{|l|c|c|c|c|c|}
\hline \multicolumn{1}{|c|}{ Configuration } & 1 & 2 & 3 & 4 & 5 \\
\hline Parameters & & 120 & 120 & 120 & 90 \\
\hline Absorber angle, $\theta\left[^{\circ}\right]$ & 1.0 & 2.0 & 2.0 & 2.0 & 2.0 \\
\hline Absorber thickness, $d[\mathrm{~cm}]$ & 22.5 & 22.5 & 24.5 & 22.5 & 22.5 \\
\hline $\begin{array}{l}\text { Distance between drums and core } \\
\text { centers, } R[\mathrm{~cm}]\end{array}$ & 5.5 & 5.5 & 6.0 & 5.5 & 5.5 \\
\hline Drum outer radius, $r[\mathrm{~cm}]$ & $1.00522 \pm 6 \mathrm{pcm}$ & $0.97907 \pm 6 \mathrm{pcm}$ & $0.98974 \pm 6 \mathrm{pcm}$ & $0.99196 \pm 6 \mathrm{pcm}$ & $1.0012 \pm 6 \mathrm{pcm}$ \\
\hline Shutdown multiplication factor ${ }^{1}[-]$ & $20.7 \pm 0.04$ & $26.0 \pm 0.04$ & $24.2 \pm 0.04$ & $24.8 \pm 0.04$ & $23.5 \pm 0.04$ \\
\hline Total reactivity worth $[\$]$ & $1.38 \pm 0.04$ & $1.76 \pm 0.04$ & $1.52 \pm 0.04$ & $1.69 \pm 0.04$ & $1.67 \pm 0.04$ \\
\hline Single drum rotation worth $[\$]$ & & & & \\
\hline
\end{tabular}

${ }^{1}$ Shutdown means all absorber elements of drums are facing the core without insertion of any SHIM rod. 


\begin{tabular}{|l|c|c|}
\hline Parameter & Reference design & Upgraded design \\
\hline Drum number [-] & 6 & 12 \\
\hline Core barrel inner/outer diameter $[\mathrm{cm}]$ & $98 / 100$ & $60 / 62$ \\
\hline Primary vessel inner diameter $[\mathrm{cm}]$ & 140.0 & 86.3 \\
\hline Wire spacer diameter $[\mathrm{mm}]$ & 0.0 & 1.4 \\
\hline Total reactivity worth $[\$]$ & $36 \pm 1$ & $24.0 \pm 0.1$ \\
\hline Single drum rotation worth $[\$]$ & $4.0 \pm 0.1$ & $1.64 \pm 0.03$ \\
\hline
\end{tabular}



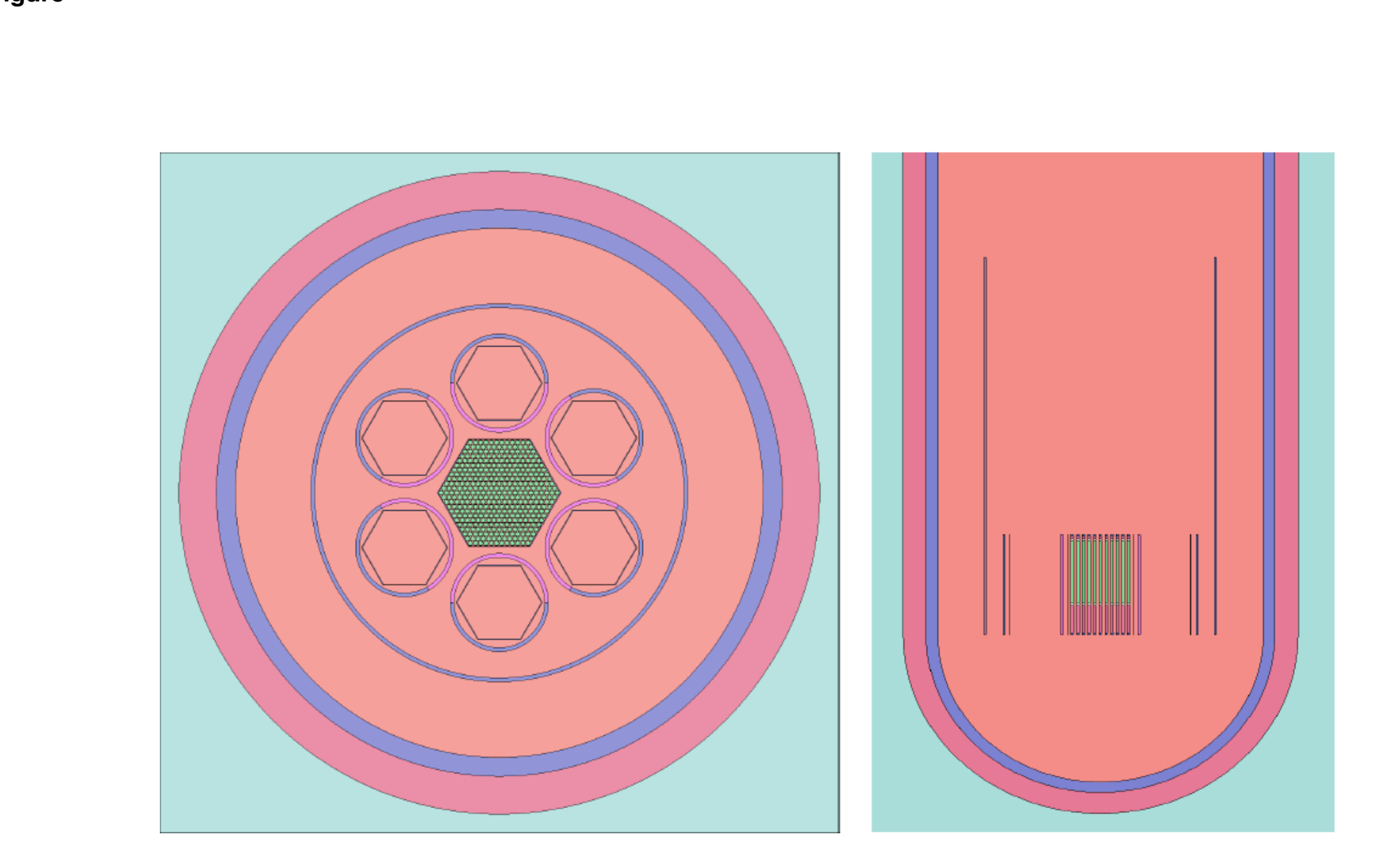

Figure
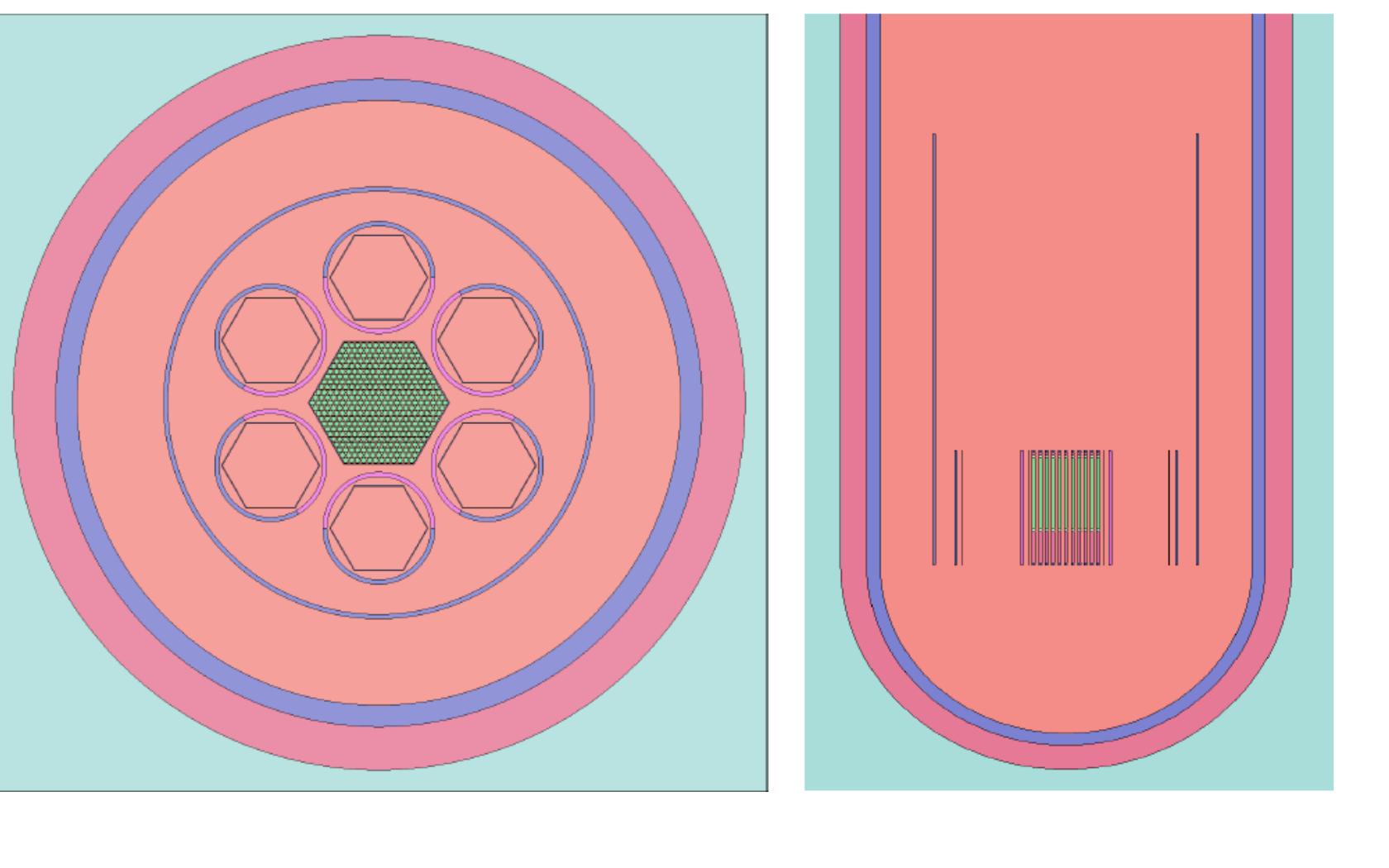


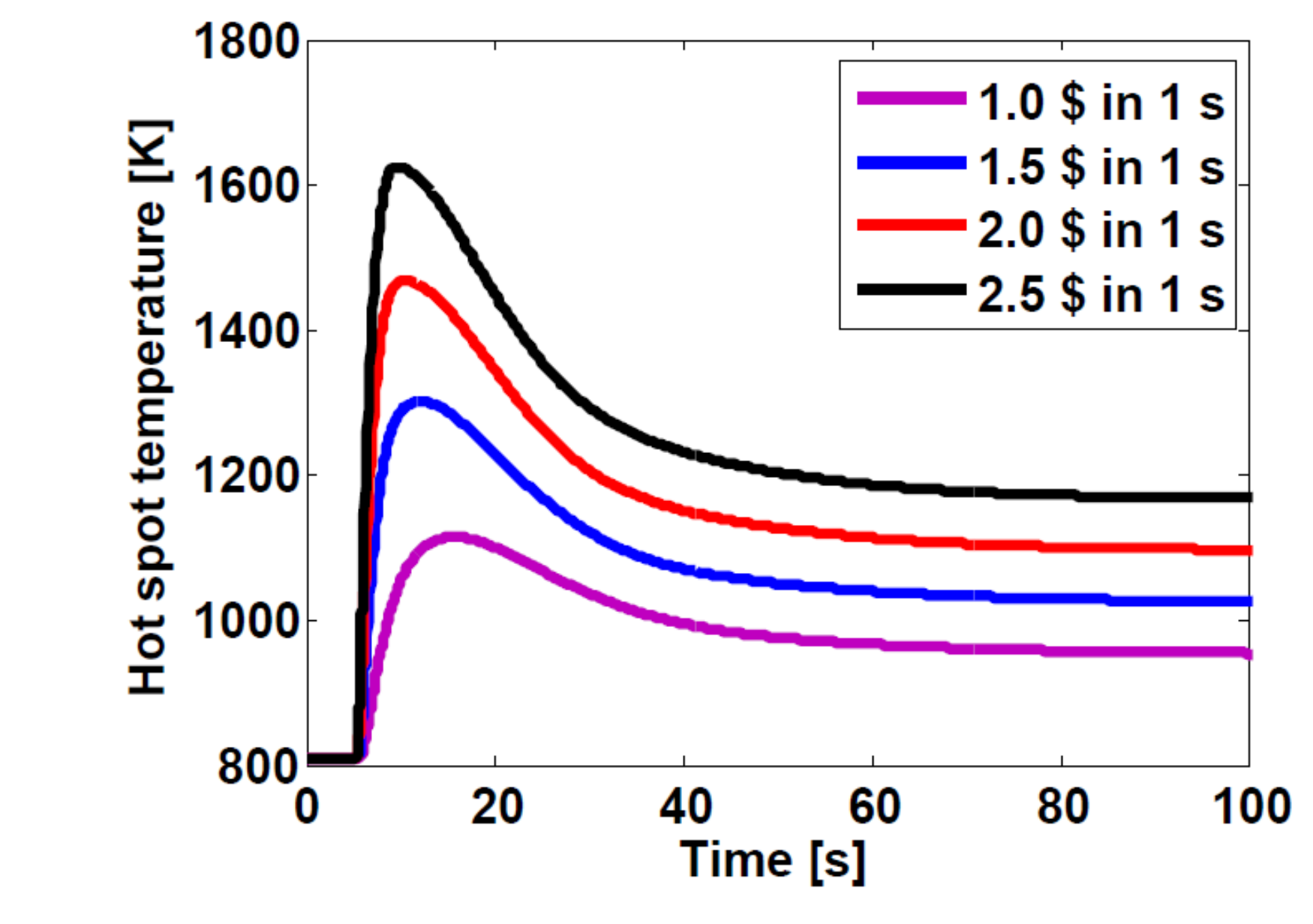

Figure

.

.

.




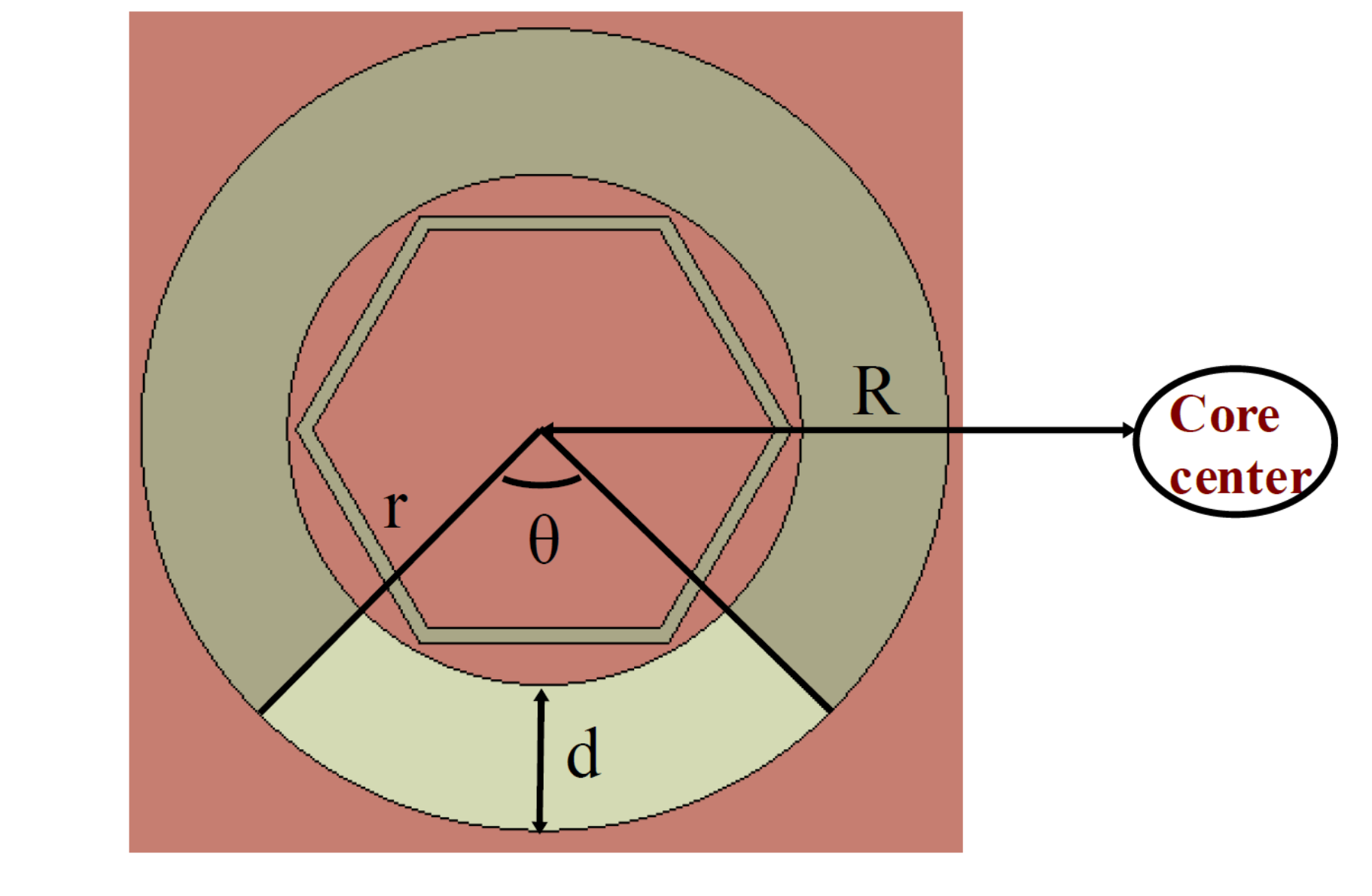

Figure .

$(2+2$$$
\text { . }
$$$$
\text { . }
$$

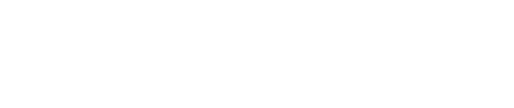
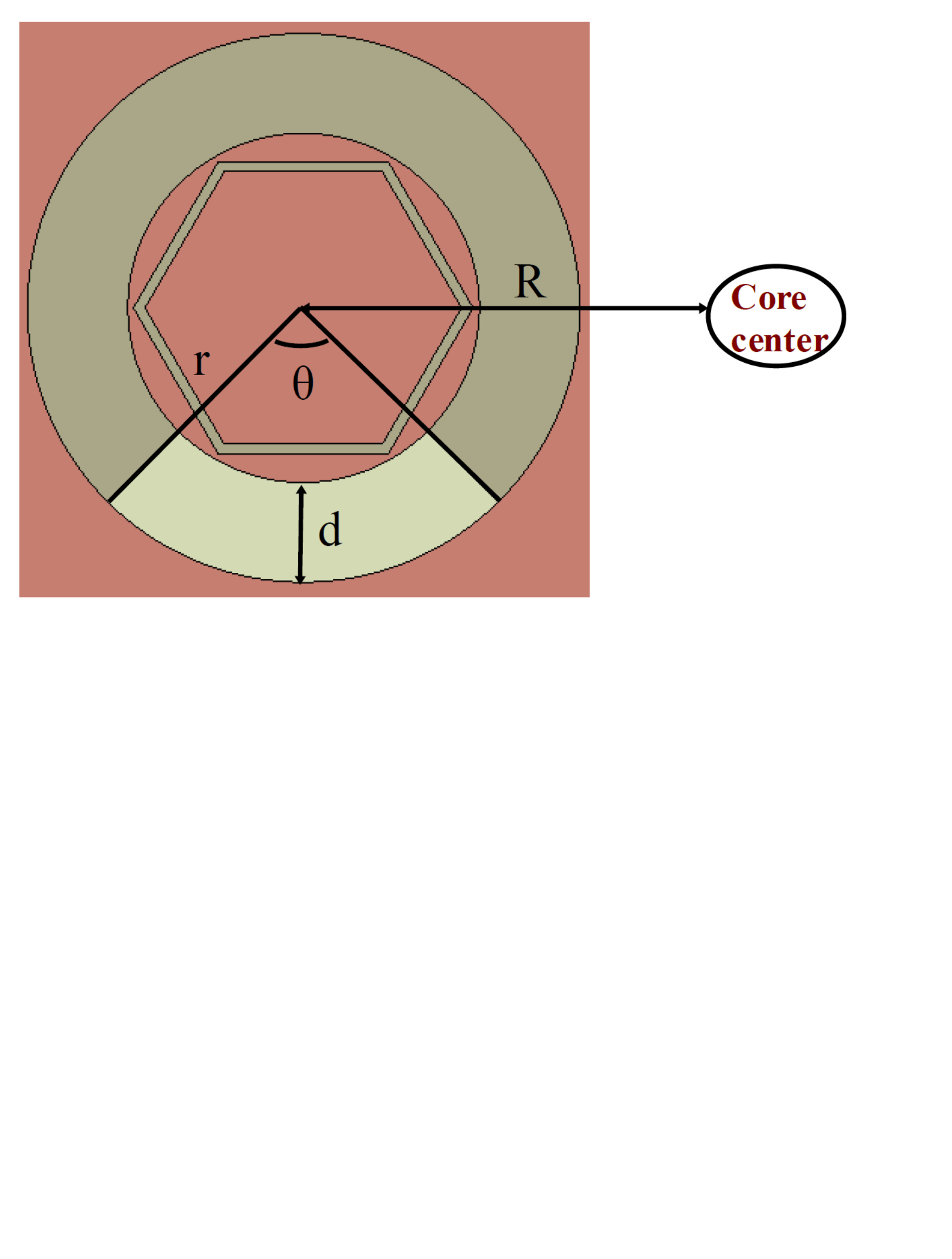
Figure

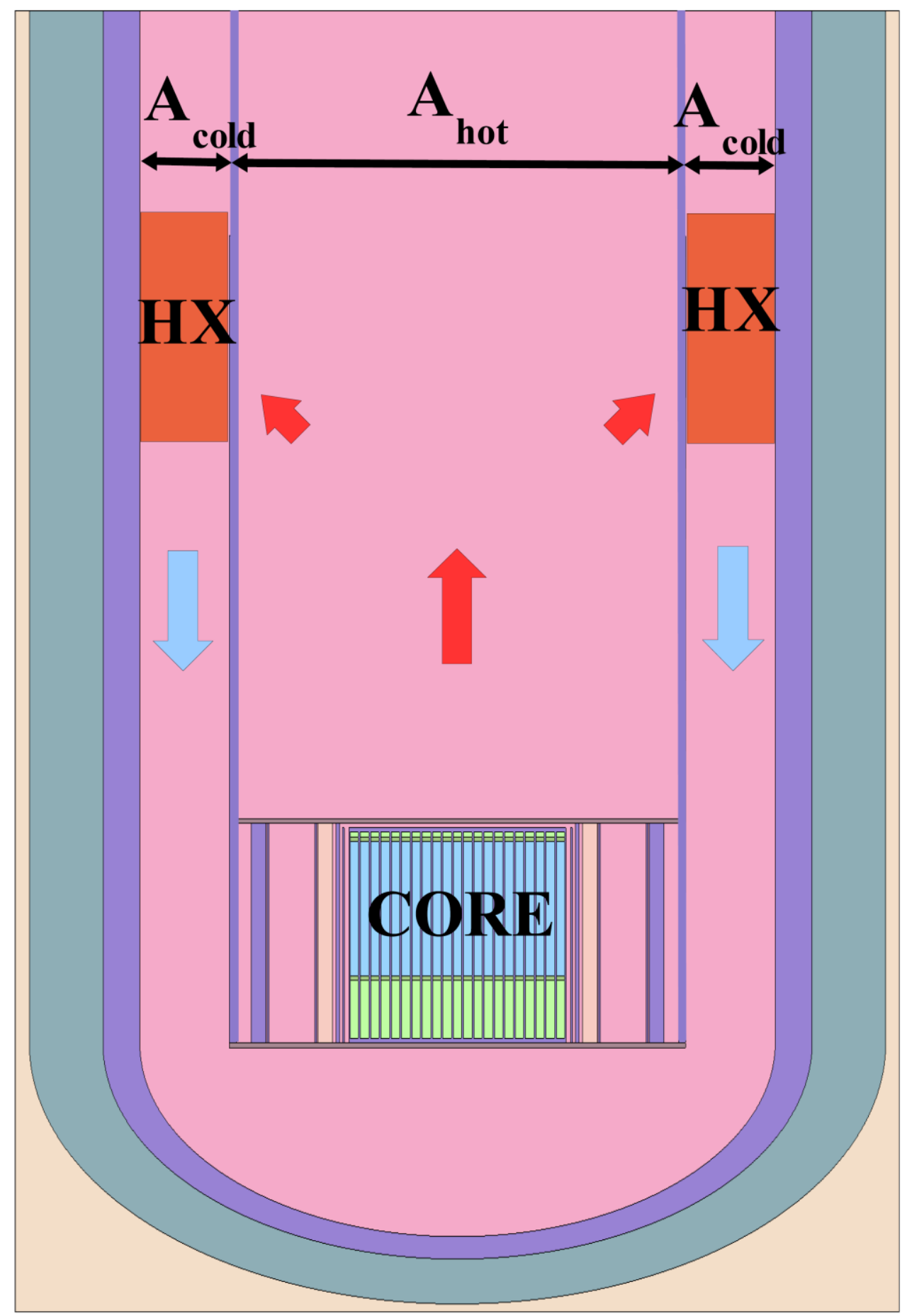




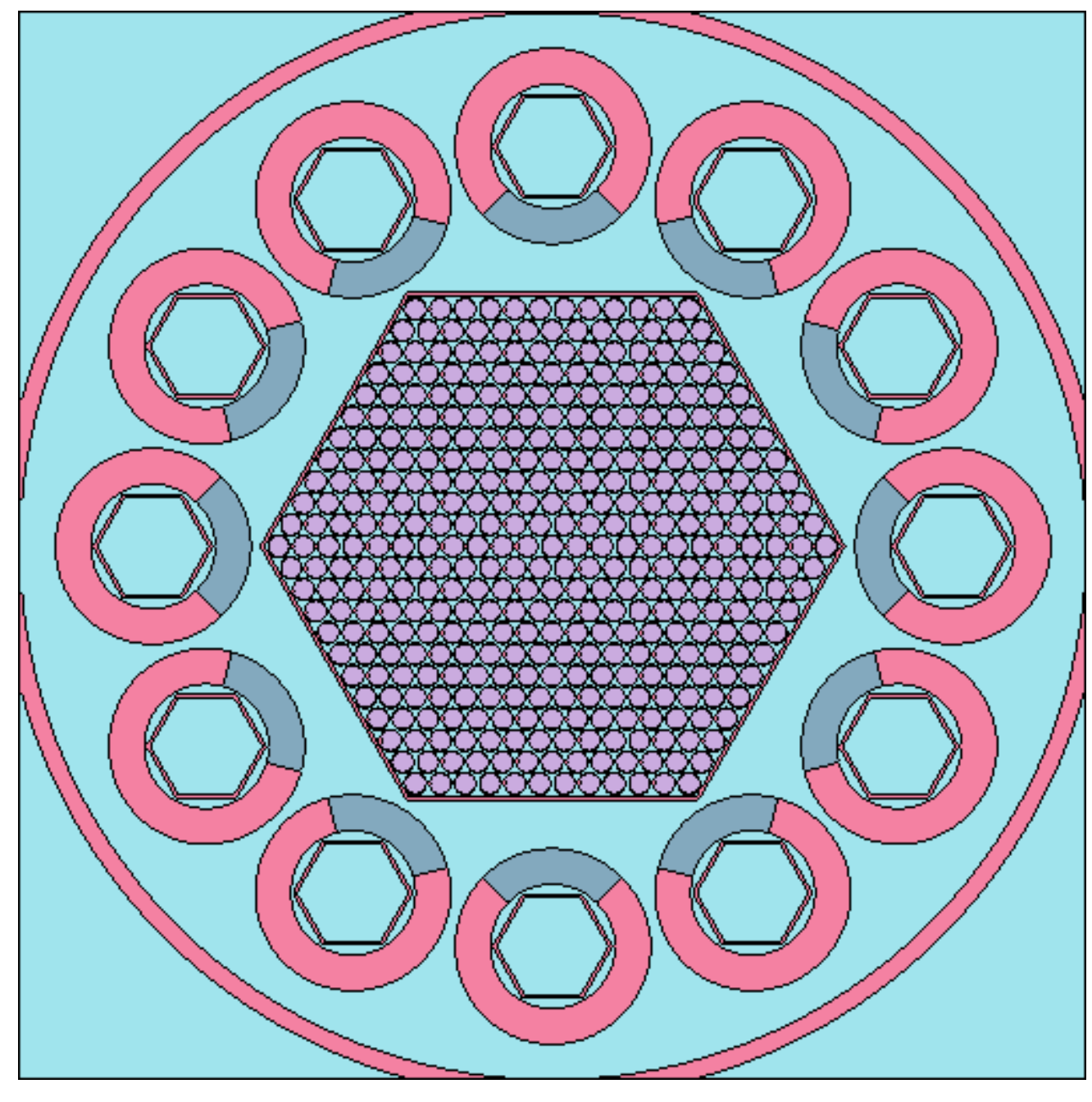

(n) 
Pool with gas

Pipe

Outlet plenum
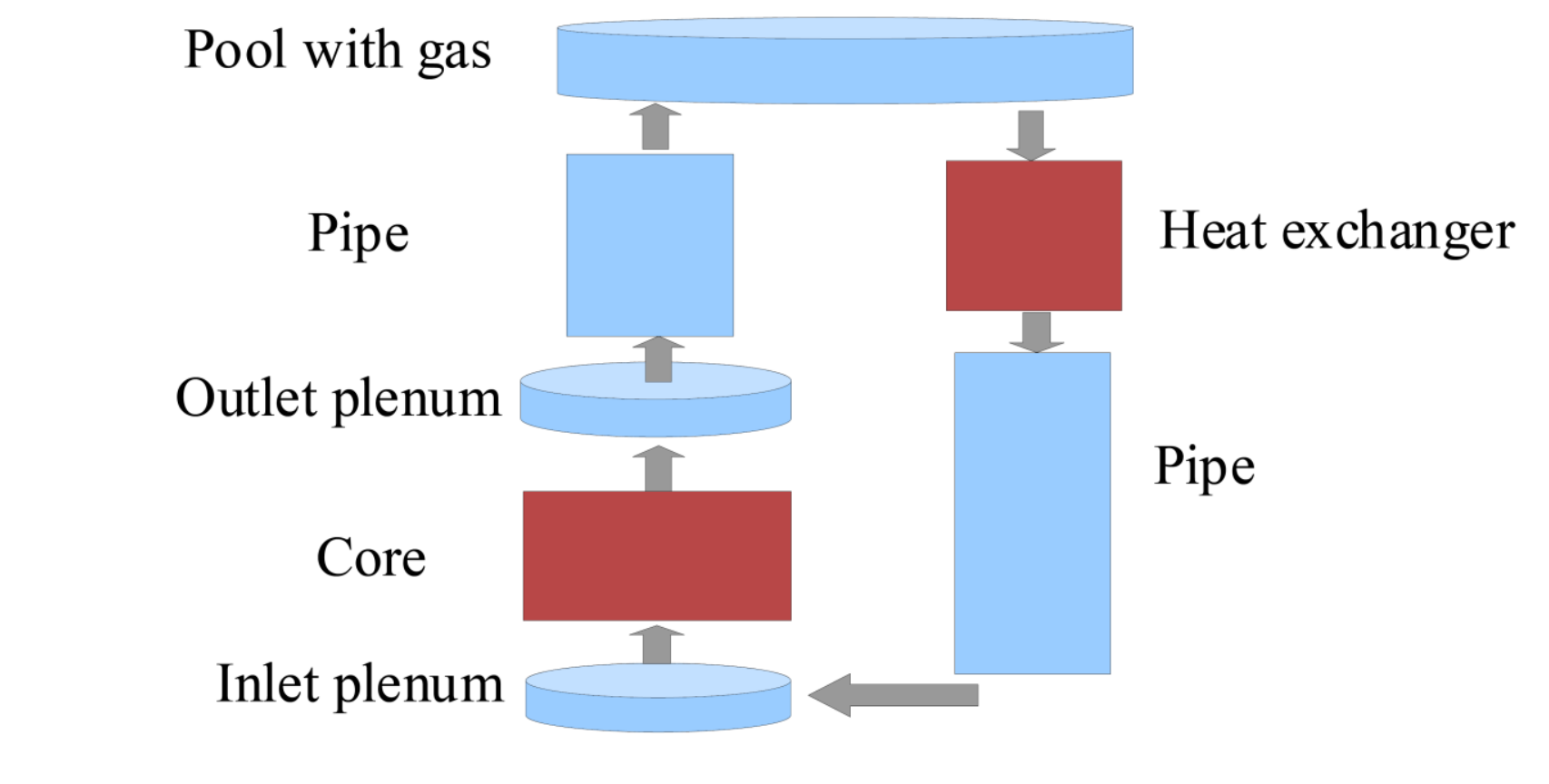

\section{Figure}

.

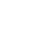

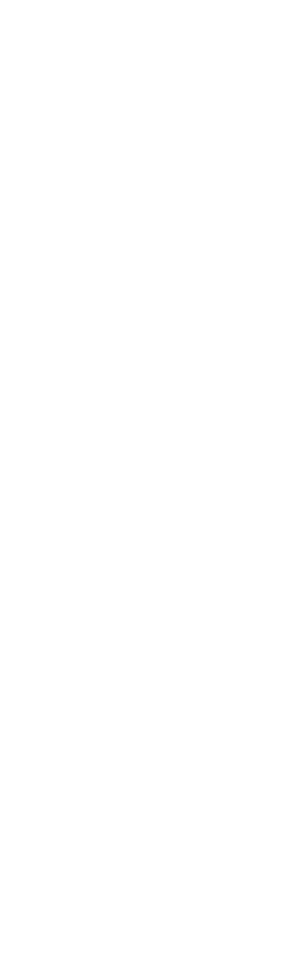

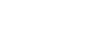

-
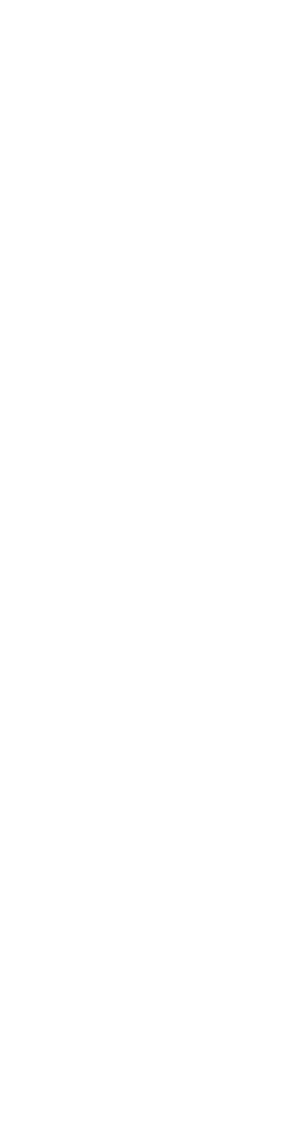


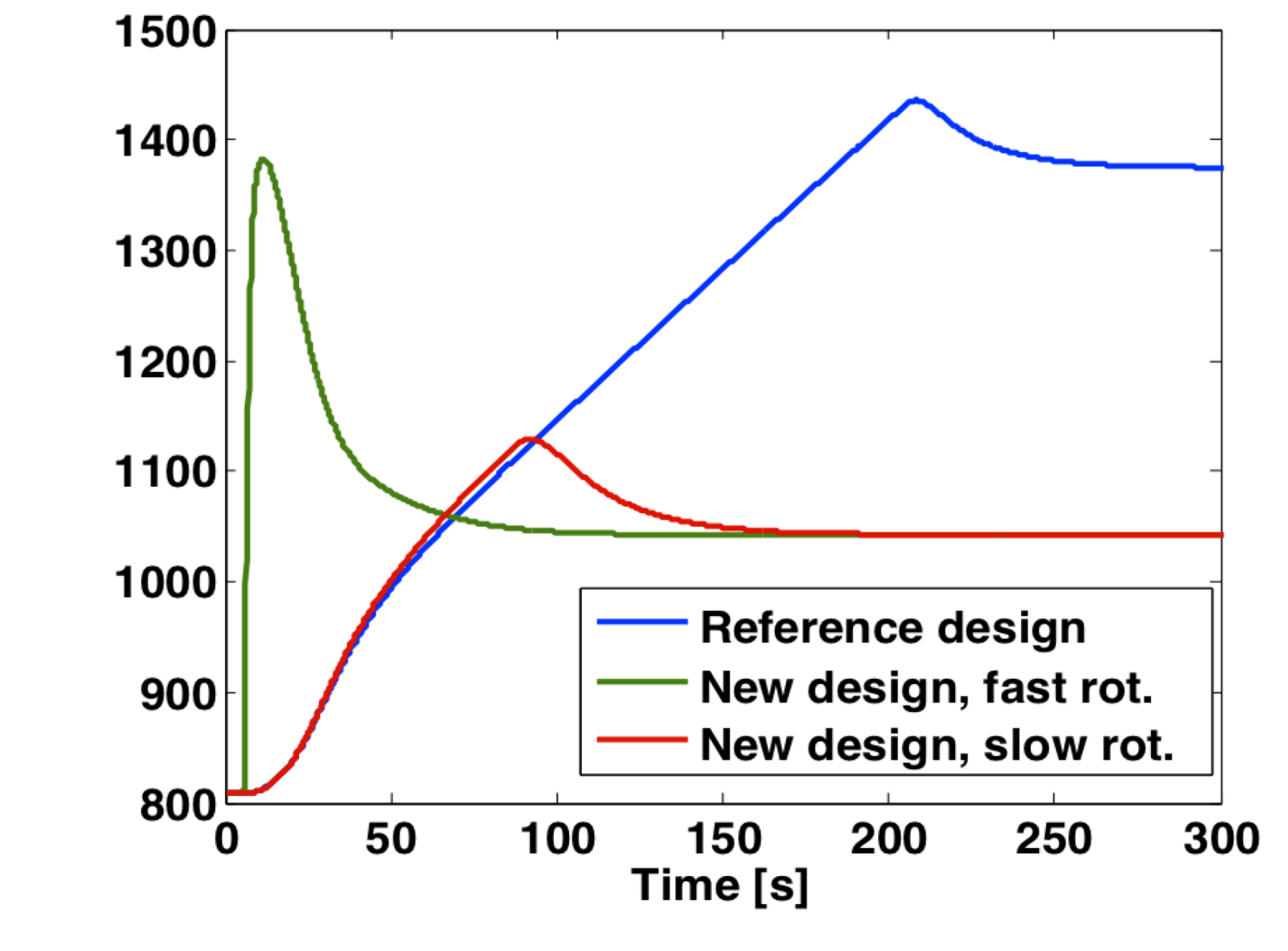

Figure

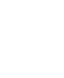

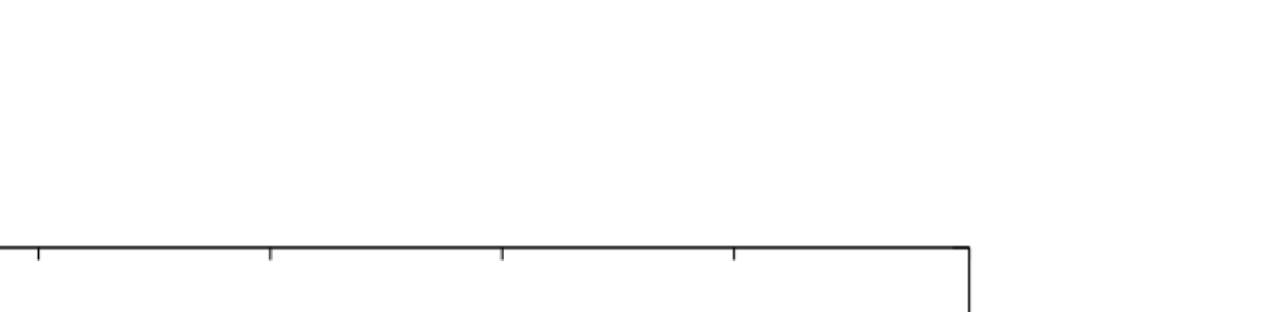

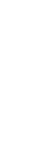




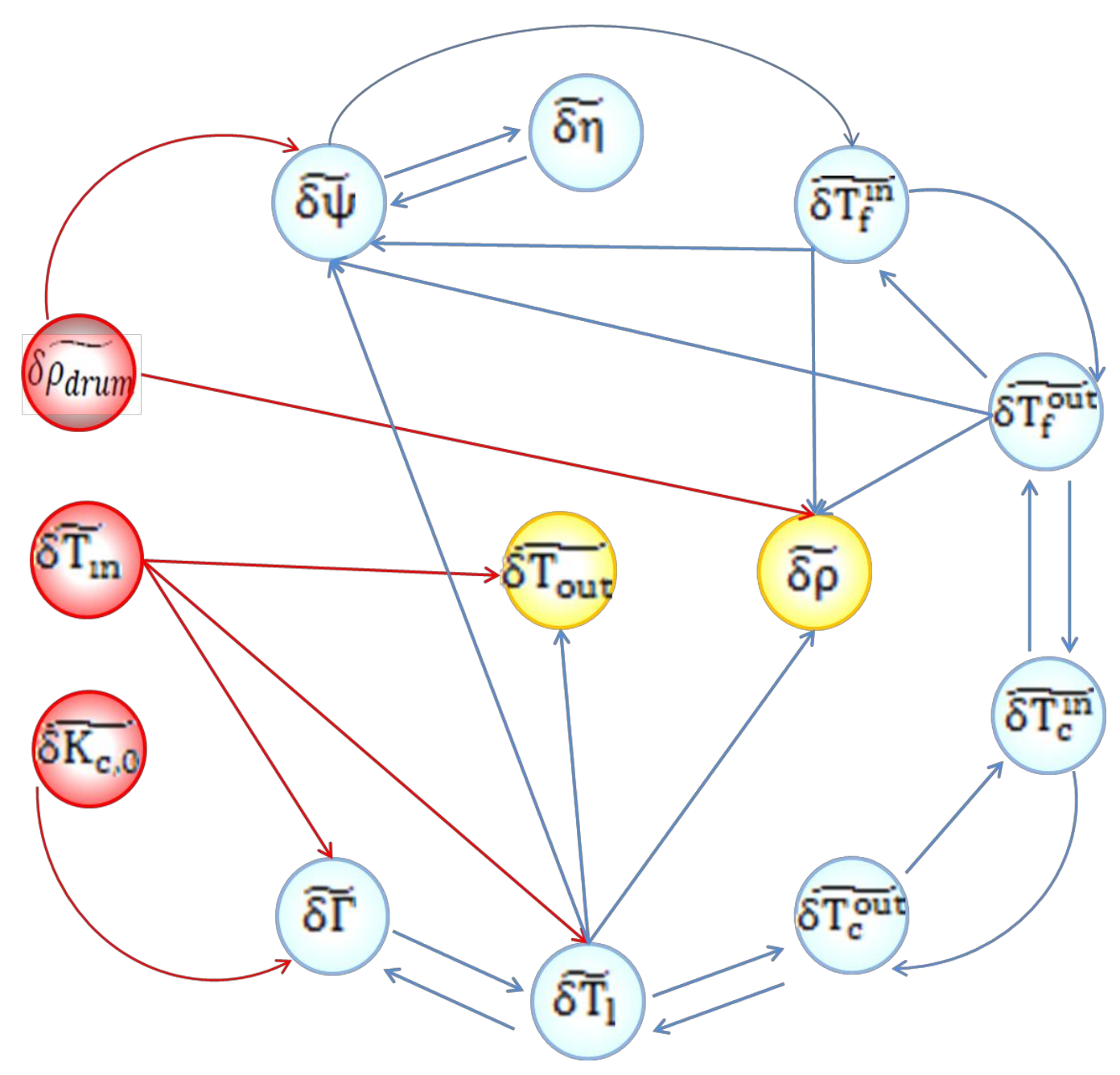

Figure 

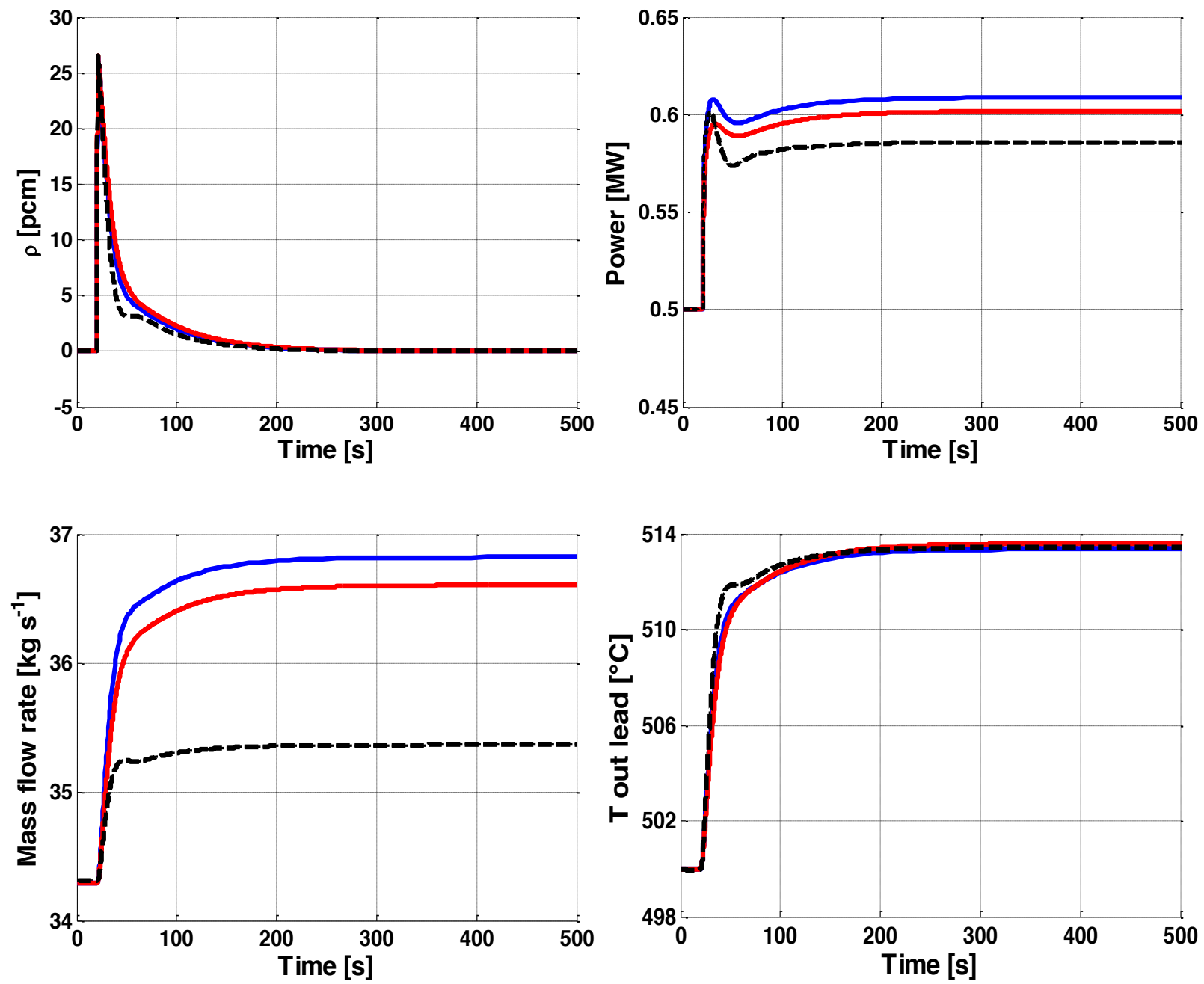